\title{
Hypercalcemia and Extensive Chest Metastasis of Vulvar Squamous Cell Carcinoma
}

\author{
Ernestina Mota ${ }^{1}$, Isabel Paulos Mesquita ${ }^{1}$, Carlos Pires ${ }^{1}$, Rui MM Vitorino ${ }^{2}$ \\ ${ }^{1}$ Serviço de Medicina 2, Hospital Santa Maria, Centro Hospitalar Lisboa Norte, Lisbon, Portugal \\ ${ }^{2}$ Serviço de Medicina, Hospital Santa Maria, Faculdade de Medicina de Lisboa, Centro Hospitalar Lisbona Norte, Lisbon, Portugal
}

Doi: 10.12890/2019_001218- European Journal of Case Reports in Internal Medicine - @ EFIM 2019

Received: $17 / 07 / 2019$

Accepted: 26/07/2019

Published: 02/09/2019

\begin{abstract}
How to cite this article: Mota E, Paulos Mesquita I, Pires C, Vitorino RMM. Hypercalcemia and extensive chest metastatis of vulvar squamous cell
\end{abstract} carcinoma. EJCRIM 2019;6: doi:10.12890/2019_001218.

Conflicts of Interests: The Authors declare that there are no competing interest

This article is licensed under a Commons Attribution Non-Commercial 4.0 License

\section{ABSTRACT}

A 73-year-old woman with a diagnosis of vulvar carcinoma submitted to curative surgery 5 years previously, presented to the emergency department with prostration and vulvar haemorrhage. Although the gynaecological examination was unremarkable, she had a mass in the left chest wall and hypercalcemia. A CT scan of the thorax revealed a voluminous left hemithorax mass invading the mediastinum, lung, pleura and chest wall. Ultrasound-guided biopsy of the mass showed infiltration by a well-differentiated keratinizing squamous cell carcinoma (SCC). This case report describes an extremely rare metastatic pattern in vulvar SCC concomitant with paraneoplastic hypercalcemia.

\section{LEARNING POINTS}

- Pulmonary metastasis of vulvar carcinoma with chest wall invasion should be included in the list of rare manifestations of squamous cell carcinoma.

- Hypercalcaemia is common in squamous cell carcinoma but rare in vulvar carcinoma, and is associated with a bad prognosis.

\section{KEYWORDS}

Squamous cell carcinoma of the vulva, paraneoplastic hypercalcemia, pulmonary metastasis of vulvar squamous cell carcinoma

\section{CASE DESCRIPTION}

We present the case of a 73-year-old woman, with a history of vulvar lichen sclerosus, who had been diagnosed 5 years previously with vulvar squamous cell carcinoma (SCC) FIGO stage Ib (T1bNOMO) and submitted to curative surgery that included right hemivulvectomy and sentinel lymph node sectioning. She presented to our emergency department with vulvar haemorrhage and a 1-month history of prostration. She was pale and dehydrated but haemodynamically stable. Chest inspection revealed a mass in the left hemithorax (Fig. 1), which was $6 \mathrm{~cm}$ in diameter, protruded out of the chest wall, and was painless. The mass had an elastic consistency, was adherent to the deep planes, and was accompanied by dullness upon percussion and decreased vesicular breath sounds on auscultation.

The mass had an elastic consistency, was adherent to the deep planes, and was accompanied by dullness upon percussion and decreased vesicular breath sounds on auscultation. The gynaecological examination was unremarkable, apart from the absence of the right labia majora. Laboratory tests showed normocytic normochromic anaemia (haemoglobin $8.5 \mathrm{~g} / \mathrm{dl}$, mean cell volume $86.1 \mathrm{fl}$, mean corpuscular haemoglobin $28.3 \mathrm{pg}$ ), raised inflammatory markers with neutrophilic leucocytosis of $17.640 \times 10^{9} / \mathrm{I}$ and a C-reactive protein level of 16.6 $\mathrm{mg} / \mathrm{dl}$, hypercalcemia with corrected calcium for serum albumin of $12.4 \mathrm{mg} / \mathrm{dl}$, ionized calcium of $1.60 \mathrm{mg} / \mathrm{dl}$, and PTH of $8.5 \mathrm{pg} / \mathrm{ml}$. Renal function, electrolytes, liver transaminases, lactate dehydrogenase and coagulation were within the normal reference values. 
Chest radiography, which showed homogeneous hypotransparency in the medial third of the left lung field (Fig. 2), and CT scans revealed a solid voluminous mass in the upper left hemithorax $(7 \times 6 \times 6 \mathrm{~cm})$, with necrosis and invading the mediastinum, lung, pleura and chest wall, suggestive of metastization, without lymphadenopathy or other masses (Figs. 3 and 4).

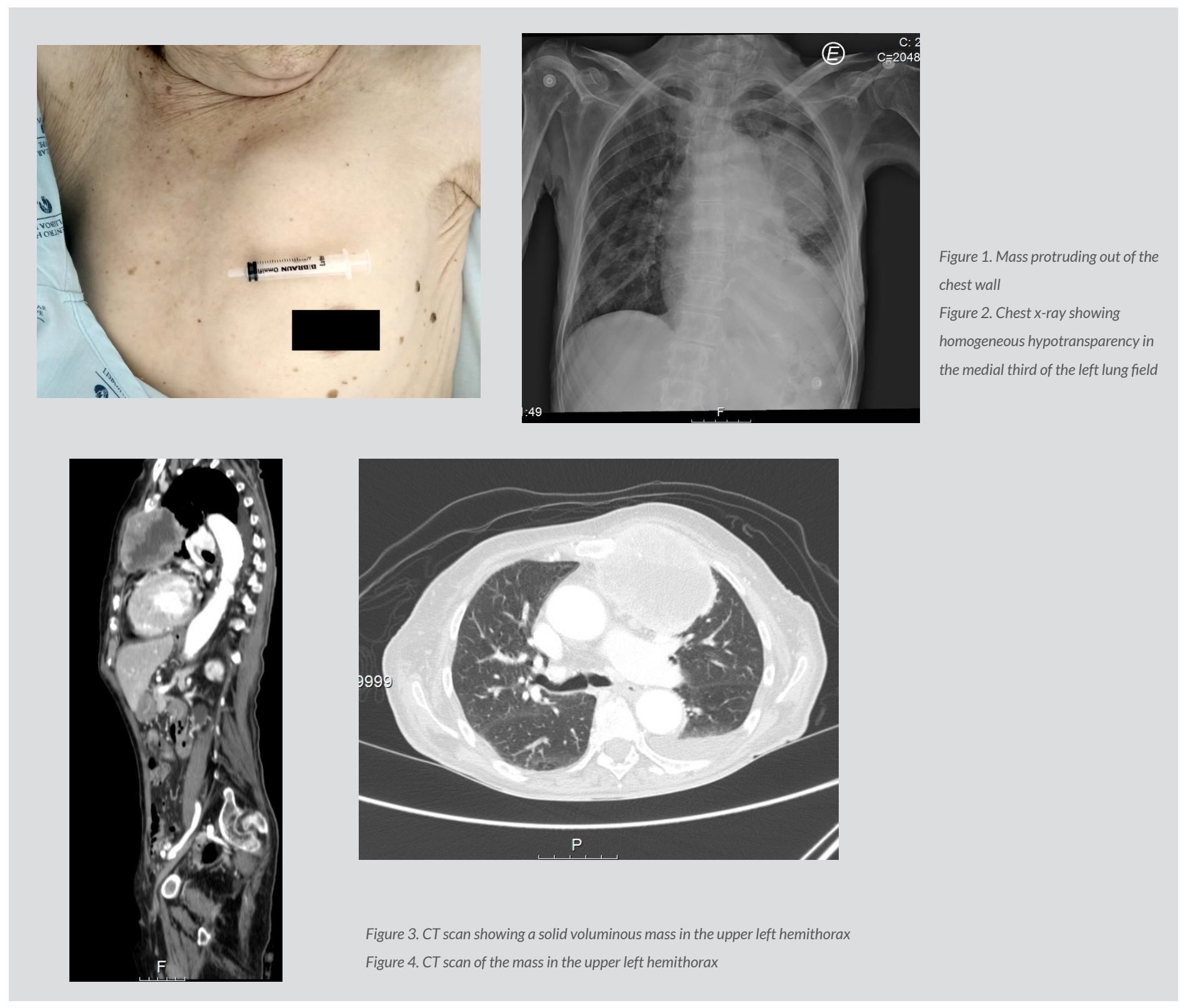

\section{DISCUSSION}

Carcinoma of the vulva is a rare tumour, accounting for $4 \%$ of all gynaecological malignancies, with an incidence of two to seven cases per 100,000 women. In about $90 \%$ of cases the histological type is SC ${ }^{[1]}$, which includes two aetiological subtypes with bimodal distribution. The classic type is related to human papilloma virus (HPV) infection, occurs in younger women and is associated with high-risk sexual activity. Older women are more likely to have HPV-negative disease and there is an association with vulvar lichen sclerosus ${ }^{[2]}$. Although metastization is rare with haematogenous dissemination to distant sites occurring in only $8-12 \%$ of patients ${ }^{[3]}$, the most common sites for metastasis are the lung, bone, liver and lymph nodes ${ }^{[4]}$. When metastization occurs, there is usually a low response to surgery/radiotherapy, with a 5 -year survival rate of less than $5 \%{ }^{[5]}$. The immunohistochemical study panel for lung carcinomas frequently includes staining for p16, cytokeratins 7 (CK7) and 20 (CK20), and thyroid transcription factor (TTF-1). CK7 and CK20 are usually negative in SCC except that 
of cervical origin, and so its value is limited in assessing the origin of the SCC. TTF-1 could indicate a lung origin, but is rarely positive in SCC. Stain for p16 can differentiate between HPV-positive and HPV-negative lesions, and, if positive, could suggest origins other than the lung ${ }^{[6]}$, or metastization if both tissues are $\mathrm{p} 16$ positive. In view of this, immunohistochemical differentiation between lung metastasis of vulvar SCC and primary lung carcinoma is difficult and frequently relies on clinical judgement. In our case, both lung and vulvar tissues were negative for 16 and thus it was not possible to differentiated on this basis.

However, considering the characteristics of the mass, namely its peripheral location invading the chest wall without the presence of nodal, liver or adrenal metastization typical in primary non-small cell carcinomas of the lung with this staging ${ }^{[6,7]}$, we assumed that the mass was most likely a pulmonary metastasis of the vulvar SCC. Although metastization of vulvar SCC to the lung has been described in the literature, in our case the metastasis presented as an unusually voluminous and extensively invasive mass as opposed to the solitary or multiple lung nodules that have been described ${ }^{[4]}$.

Paraneoplastic hypercalcemia frequently complicates SCC but is rarely seen with vulvar carcinomas ${ }^{[8,9]}$ and is associated with a bad prognosis ${ }^{[10]}$. The laboratory results suggested the diagnosis of malignant humoral hypercalcemia and the patient was treated accordingly with normalization of serum levels of calcium. After multidisciplinary discussion involving oncology, gynaecology, radiotherapy and surgery clinicians, it was decided that the patient did not meet the criteria for curative treatment and she was proposed for best supportive care in a palliative care unit.

In conclusion, this case report describes two rare manifestations of vulvar SCC, namely metastasis with invasion of the chest wall and hypercalcemia developing as late as 5 years after excision of the primary tumour.

\section{REFERENCES}

1. Meelapkij P, Suprasert P, Baisai O. Treatment outcomes of patients with squamous cell carcinoma of the vulva: the largest series from a tertiary care hospital. Obstet Gynecol Int 2018;2018:4723167.

2. Buchanan T, Mutch D. Squamous cell carcinoma of the vulva: a review of present management and future considerations. Expert Rev Anticancer Ther 2019;19:43-50.

3. Agrawal A, Wood KA, Giede CK, Chibbar R. A case of kidney metastasis in vulvar squamous cell carcinoma: a case report and review of literature. Case Rep Clin Med 2013;2:306309.

4. Prieske K, Haeringer N, Grimm D, Trillsch F, Eulenburg C, Burandt E, et al. Patterns of distant metastasis in vulvar cancer. Gynecol Oncol 2016;142:427-434.

5. Sukur, YE, Gözüküçük M, Berker B. Hypercalcemia associated with early recurrence of vulvar cancer. Arch Gynecol Obstet 2010;281:117-118.

6. Pereira TC, Share SM, Magalhães AV, Silverman JF. Silverman JF. Can we tell the site of origin of metastatic squamous cell carcinoma? An immunohistochemical tissue microarray study of 194 cases. Appl Immunohistochem Mol Morphol 2011:19:10-14.

7. Milovanovic IS, Stjepanovic M, Mitrovic D, Mitrovic D. Distribution patterns of the metastases of the lung carcinoma in relation to histological type of the primary tumor: an autopsy study. Ann Thorac Med 2017;12:191-198.

8. Alkatout I, Schubert M, Garbrecht N, Weigel MT, Jonat W, Mundhenke C, et al. Vulvar cancer: epidemiology, clinical presentation and management options. Int J Womens Health 2015;7:305-313.

9. Malangone S, Campen CJ. Hypercalcemia of malignancy. J Adv Pract Oncol 2015;6:586-592.

10. Pelosof LC, Gerber DE. Paraneoplastic syndromes: an approach to diagnosis and treatment. Mayo Clinic Proc 2010;85:838-854. 